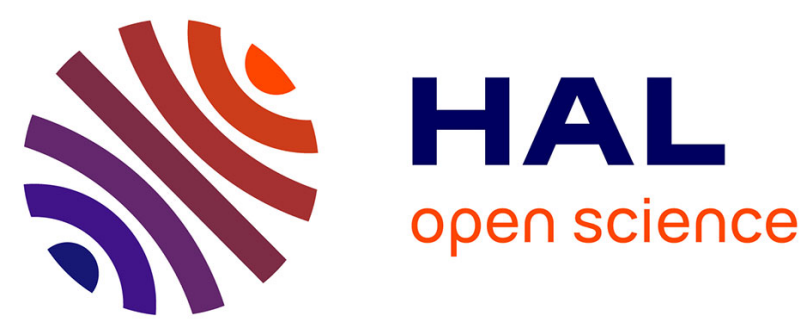

\title{
High-strain, high-strain-rate deformation of tantalum and tantalum-tungsten alloys
}

\author{
K. Vecchio
}

\section{To cite this version:}

K. Vecchio. High-strain, high-strain-rate deformation of tantalum and tantalum-tungsten alloys. Journal de Physique IV Proceedings, 1994, 04 (C8), pp.C8-301-C8-306. 10.1051/jp4:1994845 . jpa00253400

\section{HAL Id: jpa-00253400 https://hal.science/jpa-00253400}

Submitted on 1 Jan 1994

HAL is a multi-disciplinary open access archive for the deposit and dissemination of scientific research documents, whether they are published or not. The documents may come from teaching and research institutions in France or abroad, or from public or private research centers.
L'archive ouverte pluridisciplinaire HAL, est destinée au dépôt et à la diffusion de documents scientifiques de niveau recherche, publiés ou non, émanant des établissements d'enseignement et de recherche français ou étrangers, des laboratoires publics ou privés. 


\title{
High-strain, high-strain-rate deformation of tantalum and tantalum-tungsten alloys
}

K.S. Vecchio

Dept. of Applied Mechanics and Engineering Sciences, University of CA, San Diego, LaJolla, CA 92093, U.S.A.

\begin{abstract}
Resumé
Sous certaines conditions de vitesses élevées de déformation, la déformation plastique peut être supposée adiabatique et une augmentation importante de température se produit en grandes deformations. Dans cette étude, du tantale et des alliages de tantale-tungstène ont été soumis à des grandes déformations de cisaillement en grandes vitesses. Des échantillons specialement dessinés ont été utilisés dans une barre de Hopkinson. La déformation est suivied'un refroidissement à une température en dessous de la moitié de la temperature dû à l'échauffement adiabatique en moins d'une milliseconde. L'analyse de microstructure par microscopic éléctronique à transmission montre que la région de bande de cisaillement consiste en une décroissance graduelle de la taille des cellules de dislocations avec l'augmentation du taux de déformation. Une analyse basée sur la restauration dynamique est utilisée pour prédire la microstructure observíe.
\end{abstract}

\begin{abstract}
Under certain high strain rate conditions, plastic deformation can be assumed to be adiabatic, and a significant temperature increase can occur at large strains. In this study, tantalum and tantalumtungsten alloys were subjected to high shear strains at high strain rate using a specially-designed stepped specimen in a Hopkinson bar. Upon completion of the deformation, the region is cooled to below one-half of the temperature achieved due to the adiabatic heating in less than one millisecond. Microstructural analysis by transmission electron microscopy revealed that the highly deformed shear-band region consisted of a gradual decrease in dislocation cell size with increasing strain. An analysis based on dynamic recovery (enabled by the adiabatic temperatures rise associated with plastic deformation), is used to predict the recovered microstructure.
\end{abstract}

\section{INTRODUCTION}

Tantalum and tantalum-tungsten alloys have been the focus of considerable research recently because of their high density, high strength, and extensive ductility, particularly at high strain rates. These properties make Ta alloys attractive candidate materials for penetrator and shaped charge applications. Constitutive equations have been developed $[1,2]$ for use in computational mechanics modelling of these metal alloys subjected to deformation under high strain rates, and applied to modelling data at strain rates up to $\sim 5 \times 10^{3} / \mathrm{s}$, but limited to relatively small strains $(\sim 0.3)$. Although most high strain rate research has focused on low strains, metals in applications such as penetrators and shaped charges must undergo extensive plastic deformation (strains of $\sim 5$ ) at strain rates of $\sim 10^{4} / \mathrm{s}$. At these large strains, the phenomenon of tensile instability can often limit the overall performance of the material [3]. The plastic deformation process at these high strain rates can be regarded as adiabatic, and at large strains can lead to a significant temperature excursion in the material. In several recent studies on high strain, high strain 
rate deformation of copper, it has been shown that these temperature excursions are sufficient to enable dynamic crystallization to occur $[4,5]$. It has been suggested that dynamic recrystallization occurs during the high strain, high strain rate deformation in copper shaped charges [6], which retards the formation of tensile instabilities leading to well-developed penetrators. This study attempts to apply the approach previously employed on copper, to the high strain, high-strain-rate deformation of tantalum and tantalum-tungsten alloys.

\section{EXPERIMENTAL TECHNIQUES}

Mechanical tests were performed at quasi-static and dynamic strain rates at temperatures from $25^{\circ} \mathrm{C}$ to $525^{\circ} \mathrm{C}$ using cylindrical compression specimens of both pure Ta and a Ta-10wt. \% W alloy. The results of these experiments were used to determine the coefficients and exponents of the constitutive equations of both Johnson-Cook [7] and Zerilli and Armstrong [1,2]. Hat-shaped specimens, shown schematically in Figure 1, were used to generate high strain, high-strain-rate deformation under controlled, prescribed conditions. The hat-shaped specimen was developed by Meyer and co-workers [8], and has a circular cross-section and a narrow overlapping region which concentrates the shear deformation. The displacement, $\delta$, illustrated in Figure 1 , is determined and controlled by a steel ring which limits the movement of the narrow end of the specimen. The specimen is dynamically compressed using a split Hopkinson bar, see Nemat-Nasser et. al. [9] for details, recovered and sectioned for analysis using both optical microscopy and transmission electron microscopy (TEM). The region of concentrated deformation is close to pure shear, and the shear stresses can be approximated based on the original dimensions of the overlap region and shear strains can be estimated by measuring the displacement, $\delta$, and determining the thickness of the shear region by optical microscopy.

Specimens for TEM were obtained by EDM trepanning $3 \mathrm{~mm}$ cylinders through the shear region parallel to the compression direction. These cylinders were sectioned into thin disks, ground to $0.2 \mathrm{~mm}$, and electropolished to perforation. In those samples where the electron transparent region did not coincide with the shear region, further thinning was pursued via cold ion-milling at liquid nitrogen temperature. TEM observations were made using a Philips CM30 electron microscope operated at $300 \mathrm{kV}$.
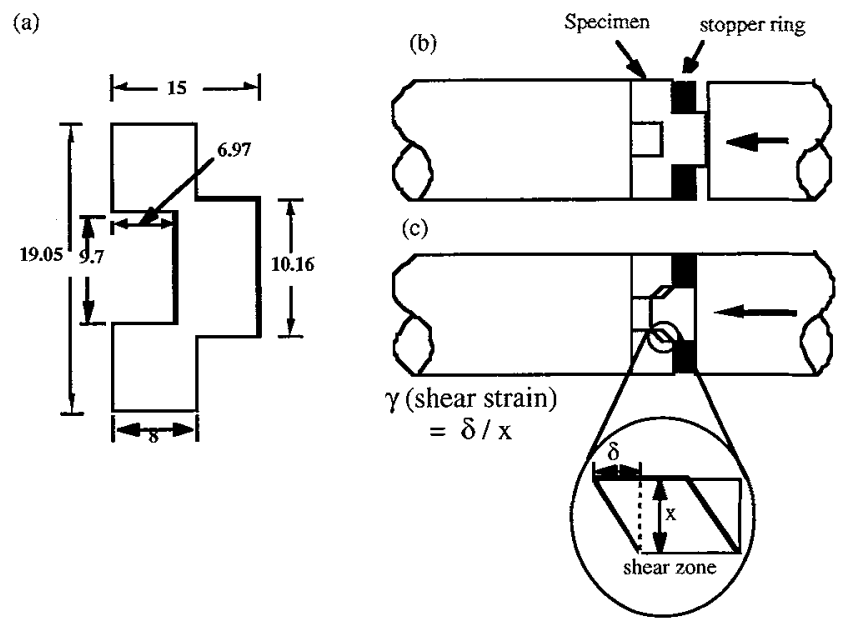

Figure 1. Schematic diagram of (a) the "hat-shaped" specimen (dimensions in mm) used to generate the high-strain-rate shear deformation, (b) before compression in Hopkinson bars, (c) after compression.

\section{RESULTS AND DISCUSSION}

\section{Mechanical Behavior and Microstructures}

Figure 2 shows the stress-strain response of both the Ta and Ta-10wt. $\% \mathrm{~W}$ at strain rates from $10^{-3} / \mathrm{s}$ to $30,000 / \mathrm{s}$ at room temperature. Additional tests conducted at a range of temperatures from $25^{\circ} \mathrm{C}$ to $525^{\circ} \mathrm{C}$ showed an significant temperature sensitivity to the stress-strain response of both alloys. These results indicate the moderate strain-rate sensitivity and dramatic temperature sensitivity of these alloys: typical 
of body-centered cubic metals where dislocation dynamics are controlled by strong Peierls stresses. From the data in Figure 2 it can be seen that the Ta-10W alloy is less sensitive to thermal softening compared to pure Ta, as indicated by the larger strain achieved before the slopes of the stress-strain curves go negative. Figure 3 shows optical micrographs of the shear regions of one specimen from each the Ta and Ta-10W materials for a shear strain of 5 . The width of the shear region increased with increasing shear strain within a given alloy, and comparison between the two alloys at a given strain indicates that the Ta-10W material produced narrower shear regions relative to the pure Ta. Higher strengths in materials generally result in an increased tendency for strain localization, and this is consistent with the differences in strength between the Ta and Ta-10W materials.
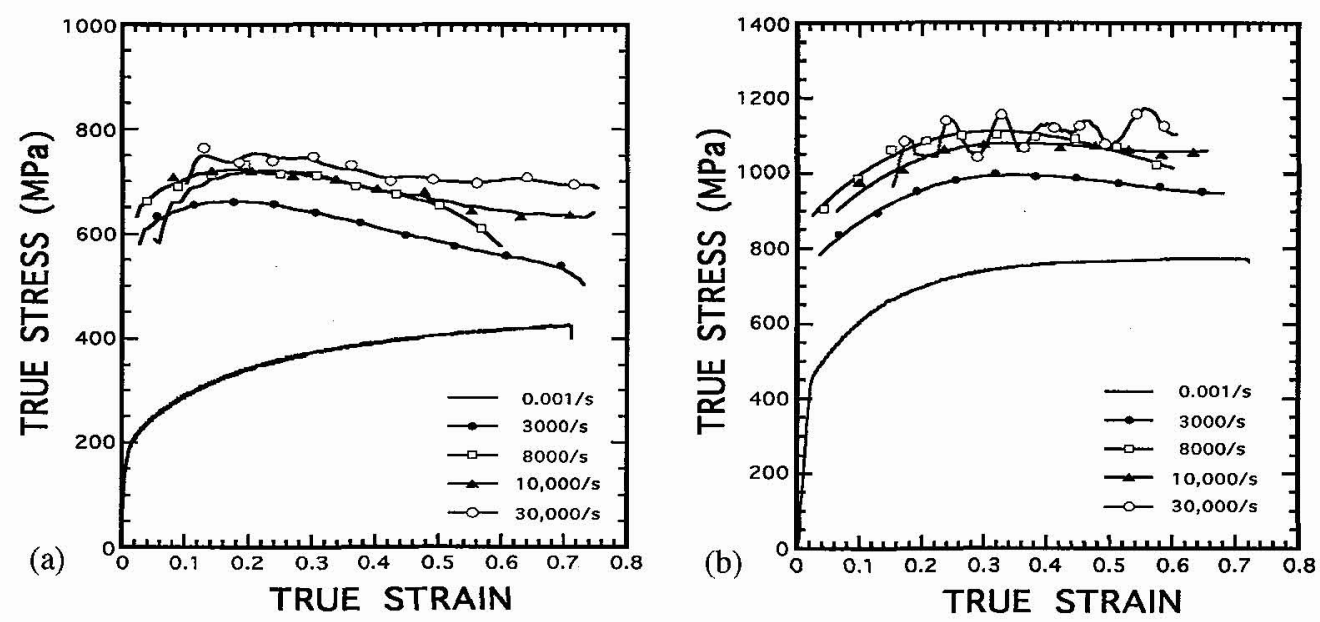

Figure 2. Stress-Strain response at room temperature from a strain rate of $0.001 / \mathrm{s}$ to $30,000 / \mathrm{s}$ for (a) pure Ta and (b) Ta-10W alloy.

(a)

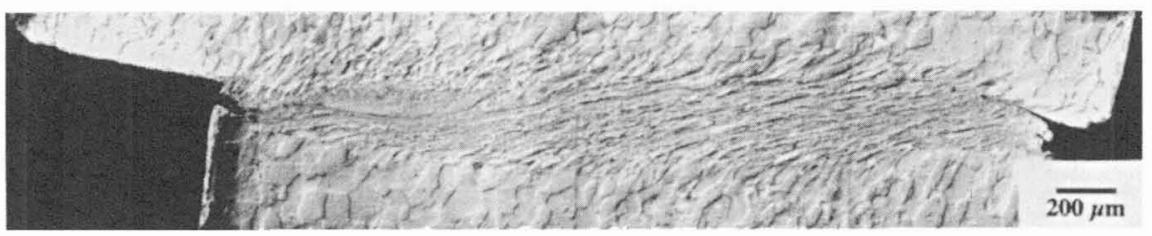

(b)

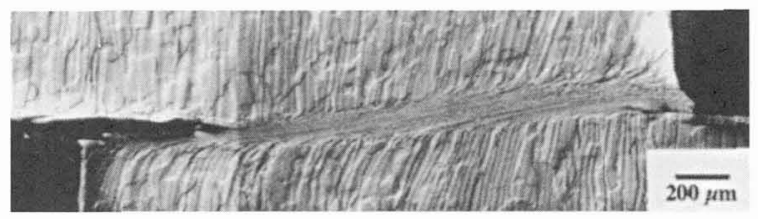

Figure 3 Optical micrographs of shear regions for a shear strain of 5 in (a) pure Ta and (b) Ta-10W.

Within the shear regions, the grain structure is unresolved by optical microscopy, and TEM was employed to elucidate this fine-scale microstructure. Figure 4 shows a sequence of TEM micrographs of the shear region from the Ta-10W alloy subjected to a shear strain of 5 . The evolved substructure was similar in both alloys at a given strain, and consisted of highly-elongated dislocation cells, generally near the edge of the shear region, and fine-scale dislocation cells and sub-grains toward the center of the shear region. However, the distribution of the shear deformation was not homogeneous across the shear region, with some areas near the center showing relatively little deformation, while certain regions adjacent to the edge of the shear region were extensively deformed. Diffraction analysis of these regions indicate that the degree of misorientation between the cells increases with decreasing cell size, as indicated by the separation of spots within ring patterns. The degree of misorientation achieved at the smallest cell sizes resulted in nearly complete ring patterns. However, the fine-scale structure did not 
contain new, dislocation-free grains, as was found in the earlier work on copper $[4,5]$. The temperature rise associated with this shear deformation in the copper experiments indicated that the evolved temperature was above the recrystallization temperature of copper, supporting the concept of dynamic recrystallization. However, the present results on Ta and Ta-10W suggests that the evolved temperature here, was not above the recrystallization temperature for these materials, and only dynamic recovery was occuring within these shear regions.

\section{Temperature Rise Calculations}

The data in the plots of Figure 2 were used to determine the coefficients and exponents of the constitutive equations by a regression analysis technique that determines the best-fit parameters for all of the data for a given alloy. The two constitutive equations employed for this analysis were: (a) the Johnson-Cook equation, given by:

$$
\sigma=\left[\sigma_{o}+\left(\varepsilon^{n} B\right)\right]\left[1+\left(C \log \left(\dot{\varepsilon} / \dot{\varepsilon}_{o}\right)\right]\left[1-\left(\frac{T-T_{o}}{T_{m}-T_{o}}\right)^{m}\right]\right.
$$

where $\sigma_{0}, \mathrm{~B}, \mathrm{n}, \mathrm{C}$, and $\mathrm{m}$ are the parameters determined by the regression analysis procedure, and $\mathrm{T}, \mathrm{T}_{\mathrm{o}}$, and $\mathrm{T}_{\mathrm{m}}$ are the current, initial or reference, and melting temperatures, respectively, $\dot{\varepsilon} / \dot{\varepsilon}_{o}$ is the ratio of test strain rate to a reference strain rate, and $\sigma$ and $\varepsilon$ are stress and strain, respectively; and (b) the Zerilli and Armstrong equation for bcc metals, given by:

$$
\sigma=\sigma_{o}+C_{1} \exp \left[-C_{3} T+C_{4} T \ln \dot{\varepsilon}\right]+C_{5} \varepsilon^{n}
$$

where $\sigma_{0}, \mathrm{C}_{1}, \mathrm{C}_{3}, \mathrm{C}_{4}, \mathrm{C}_{5}, \mathrm{n}$, are the parameters determined by the regression analysis procedure, $\dot{\varepsilon}$ is the imposed strain rate, $T$ is the test temperature, and $\sigma$ and $\varepsilon$ are stress and strain, respectively. An analysis of the fitting procedure showed that the Zerilli-Armstrong equation yielded better results over the entire strain-rate and temperature regime investigated here, with the Johnson-Cook equation tending to overestimate the stresses at strains $>0.3$. The coefficients determined by the regression analysis for each equation were then used to calculate the temperature rise associated with the high strain, high-strain-rate adiabatic deformation conditions of the hat-shaped specimen's shear regions, by incorporating the work of plastic deformation into an adiabatic temperature rise. The temperature rise can be estimated by integrating the stress-strain response at the strain rate produced in the shear region out to the shear strain achieved in the experiment. Since the temperature rise can not be derived explicitly from the results of the hat-shaped specimen, due to uncertainties associated with the shear area and shear displacements within these specimens, the temperature rise was calculated by integrating the constitutive equations, using the parameters determined by the best-fit regression analysis of the compression tests. It can be assumed that $90 \%$ of the plastic work contributed to a temperature rise. Therefore, the equations have the general form of:

$$
T=\frac{0.9}{\rho C_{p}} \int_{o}^{\varepsilon} \sigma d \varepsilon
$$

where $\rho$ is density, $C_{p}$ is the heat capacity, and $\sigma$ is the constitutive equation integrated from 0 to the final strain. The axial strain $\varepsilon$ is converted to shear strain by:

$$
\varepsilon=\ln \left(\frac{\gamma^{2}}{2}+\gamma+1\right)^{1 / 2}
$$

and axial stress is converted to shear stress by $\sigma=2 \tau$. The results of these calculations are shown in Figure 5 for both constitutive equations and alloys. In each case, the calculated temperature rise at a shear strain of 5 is well below the range of temperature normally associated with recrystallization $(0.4$ to 0.5 of the melting temperature, $\mathrm{T}_{\mathrm{m}}$ ). Integration of the Johnson-Cook equation results in higher temperature predictions compared to the Zerilli-Armstrong equation, since the Johnson-Cook equation tends to overestimate the stresses to a greater degree at increasing strain. The temperature rise calculated for the Ta-10W material is higher than the pure Ta material, irrespective of which equation is used, consistent with the higher strength of this material. This higher temperature contributes to the more localized shear deformation observed for the Ta-10W alloy compared to the pure Ta. However, the temperature rise is still insufficient to exceed the recrystallization temperature of Ta. In addition, the recrystallization temperature of $\mathrm{Ta}-10 \mathrm{~W}$ is expected to be somewhat higher than for pure $\mathrm{Ta}$, due to the higher melting temperature of $\mathrm{W}$ ( $3683 \mathrm{~K}$ for $\mathrm{W}$ compared to $3270 \mathrm{~K}$ for Ta). Figure 6 shows a comparison of the calculated temperature rise, using the Johnson-Cook equation, for the Ta and Ta-10W alloys along with the results from the earlier study on copper. Clearly, the temperature rise associated 
with the copper deformation is a much greater fraction of its melting temperature at a given strain, than it is for either the $\mathrm{Ta}$ or Ta-10W materials. In addition, it would be expected that dynamic recrystallization would be possible at a shear strain of approximately 5 in copper, consistent with the recrystallization observed at that strain in the earlier work.

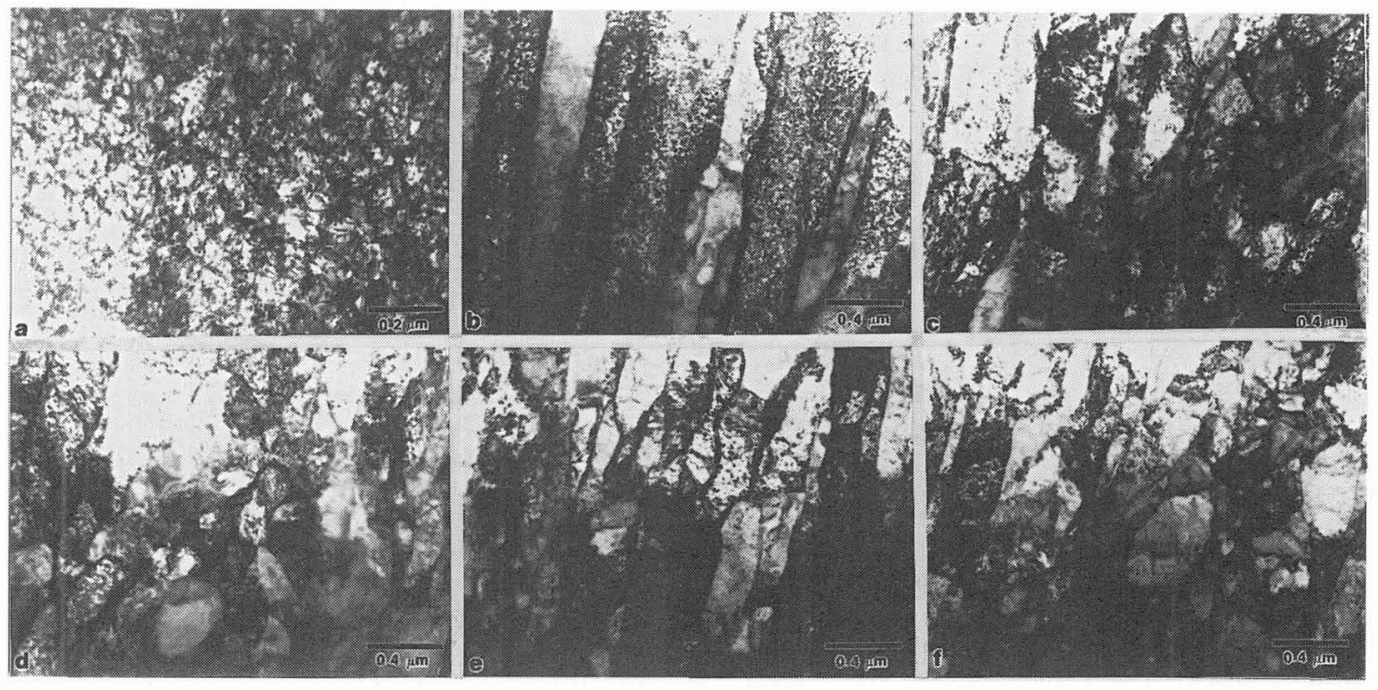

Figure 4. Sequence of TEM micrographs from the shear region of the Ta-10W alloy for a shear strain of 5; (a) outside the shear region, (b) immediately adjacent to the shear region, (c) just inside the shear region, (d) approaching the center of the shear region, (e,f) at center of shear region.
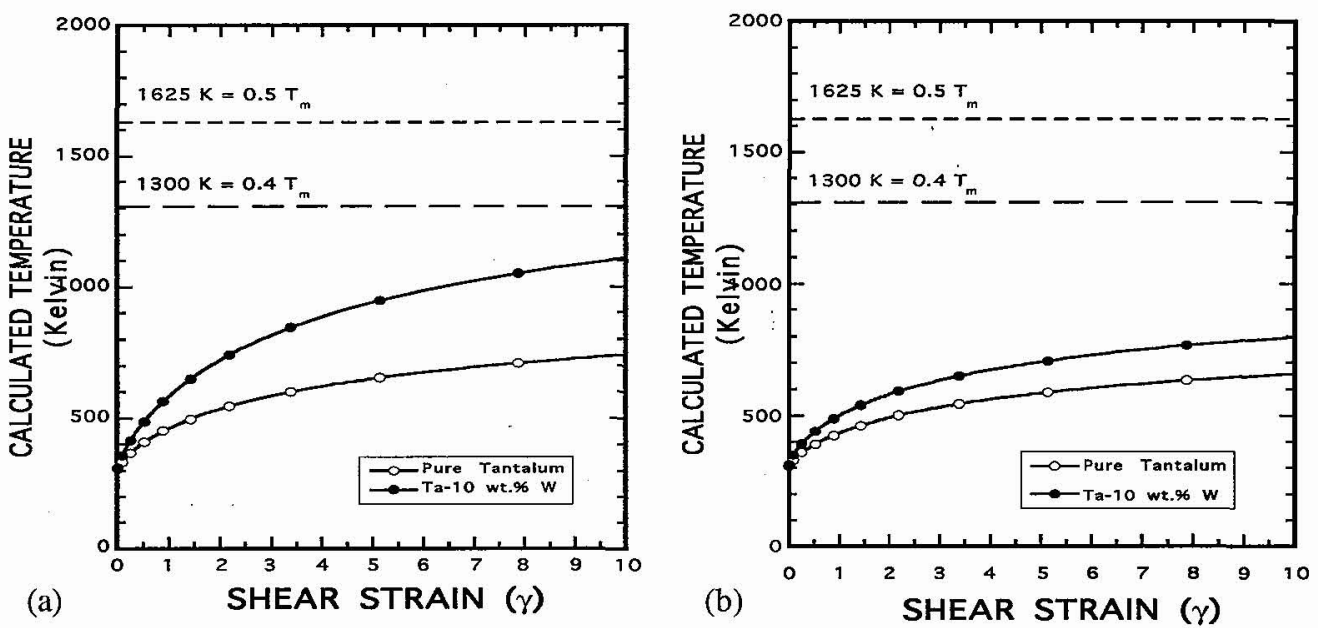

Figure 5. Calculated temperature rises for both pure Ta and Ta-10W alloy as a function of shear strain using (a) Johnson-Cook equation and (b) Zerilli-Armstrong equation.

\section{SUMMARY AND CONCLUSIONS}

Systematic experiments conducted at high strain rates to large shear strains in pure $\mathrm{Ta}$ and a Ta$10 \mathrm{wt} . \% \mathrm{~W}$ alloy indicate that dynamic recovery occurs within the highly-localized deformation region of these hat-shaped specimens. The temperature rise associated with this deformation region was insufficient to achieve dynamic recrystallization, in contrast with the conditions achieved for pure copper from an earlier study $[4,5]$. The inability to achieve a condition of dynamic recrystallization may lead to 
tensile instabilty in the formation of Ta or Ta-W shaped charges due to the inability to achieve steadystate plastic deformation (i.e. a balance between work hardening and thermal softening) facilitated by a process of dynamic recrystallization.

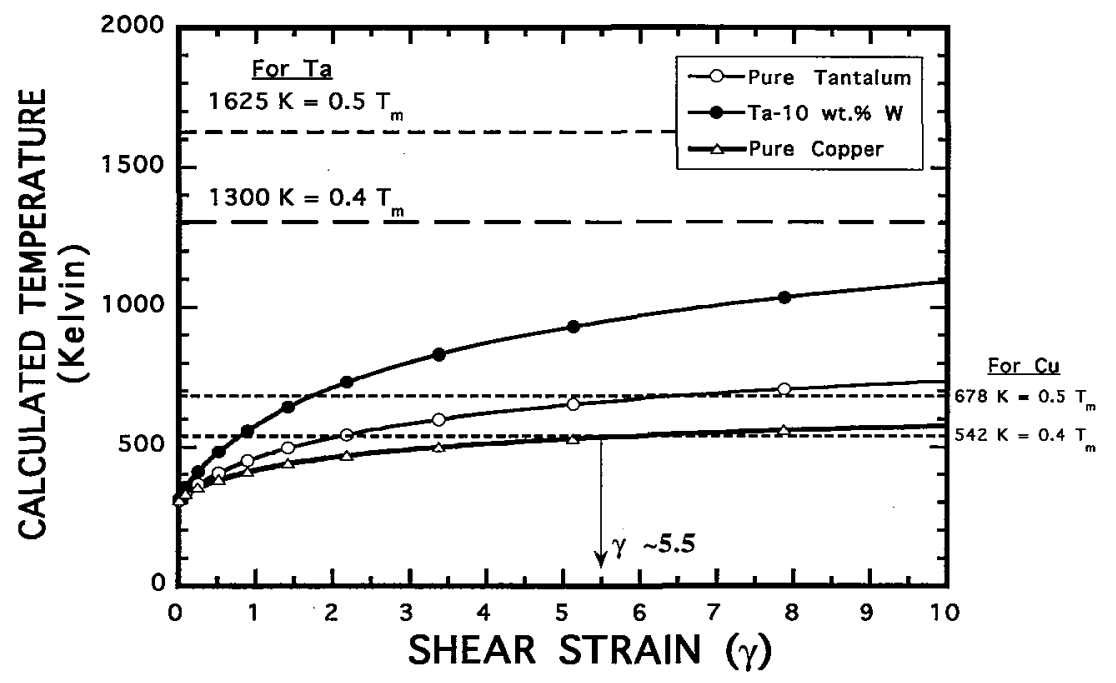

Figure 6. Calculated temperature rises for pure $\mathrm{Ta}, \mathrm{Ta}-10 \mathrm{~W}$ alloy, and pure copper (from a previous study $[4,5]$ using the Johnson-Cook equation showing the copper reaches its recrystallization temperature range at a shear strain of -5 , while the Ta and Ta-10W alloys are well below the recrystallization temperature of $\mathrm{Ta}$.

\section{ACKNOWLEDGMENTS}

The author acknowledges the support of the Army Research Office through a URI grant \# ARO-DAAL03-92-G-0108 and the National Science Foundation grant \# DMR-9110930 for this research. The assistance of Mr. Jon Isaacs in running the high-strain-rate experiments is greatly appreciated.

\section{REFERENCES}

[1] Zerilli, F. J. and R. W. Armstrong, J. Appl. Phys., 61, 1816, (1986).

[2] Zerilli, F. J. and R. W. Armstrong, J. Appl. Phys., 68 (4), 1580-1590, (1990).

[3] Brown, L. M., Met. Trans. A, 22, 1693 (1991).

[4] Meyers, M.A., Meyer, L.W., Vecchio, K.S., and Andrade, U., "High Strain, High Strain-Rate Deformation of Copper", (Journel de Physique, Colloque C3, suppl. au Journal de Physique III, Oct. 1991) 11-17.

[5] Andrade, U. M. A. Meyers, K. S. Vecchio, and A. H. Chokshi, Acta Met. et Mater., in press, 1994.

[6] Chokshi, A. H. and M. A. Meyers, Scripta Met. et Mater., 24, 605 (1990).

[7] Johnson, G. R. and W. H. Cook, Proc. 7th International Symposium on Ballistics, ADPA, The Netherlands (1983).

[8] Meyer, L.W. and Manwarig, S., in "Metallurgical Applications of Shock-Wave and High-StrainRate Phenomena," M. Dekker, N.Y., 657, (1986).

[9] Nemat-Nasser, S., J. Isaacs, and J. E. Starrett, Proc. Roy. Soc., 435A, 371, (1991). 